\title{
Urban Health Extension Program and Health Services Utilization in Northwest Ethiopia: A Community-Based Study
}

This article was published in the following Dove Press journal: Risk Management and Healthcare Policy

\author{
Sisay Molla' \\ Chalie Tadie Tsehay $\mathbb{( D}^{2}$ \\ Tsegaye Gebremedhin (iD) ${ }^{2}$ \\ 'University of Gondar Student Clinic, \\ University of Gondar, Gondar, Ethiopia; \\ ${ }^{2}$ Department of Health Systems and \\ Policy, Institute of Public Health, College \\ of Medicine and Health Sciences, \\ University of Gondar, Gondar, Ethiopia
}

Correspondence: Chalie Tadie Tsehay University of Gondar, P.O. Box: 196,

Gondar, Ethiopia

Tel +25I 918049528

Email chatadie78@gmail.com
Purpose: Ethiopia is one of the developing countries striving to achieve universal health coverage using the health extension program (HEP). However, there is limited evidence on the utilization of the urban health extension program (UHEP), particularly in the northwest part of the country. Therefore, this study aimed to assess the level of urban health extension program utilization and its associated factors in Gondar administrative city, northwest Ethiopia.

Patients and Methods: A community-based cross-sectional study was employed from March 15 to May 30, 2019. A total of 626 systematically selected mothers were interviewed using an interviewer-administered structured questionnaire. Binary logistic regression analysis was computed. In the final multivariable logistic regression analysis, a $P$-value of less than 0.05 and adjusted odds ratio (AOR) with $95 \%$ confidence interval (CI) were used to declare the factors associated with the utilization of urban health extension services.

Results: The utilization level of urban health extension services was found to be $59.5 \%$ (95\% $\mathrm{Cl}=55.8-63.6)$. The result indicated that two-fifths of the participants were not utilizing the services. Private employees $(\mathrm{AOR}=0.37,95 \% \mathrm{Cl}=0.21-0.63)$, housewives $(\mathrm{AOR}=0.36$, $95 \% \mathrm{Cl}=0.20-0.64)$, merchants $(\mathrm{AOR}=0.08,95 \% \mathrm{Cl}=0.03-0.17)$, satisfactory knowledge $(\mathrm{AOR}=4.37,95 \% \mathrm{Cl}=2.73-6.96)$, perceived accessibility of services (AOR=1.68, 95\% $\mathrm{CI}=1.02-2.74$ ), and perceived competence of HEWs (AOR $=1.97,95 \% \mathrm{Cl}=1.22-3.18$ ) were factors significantly associated with the utilization of urban health extension services.

Conclusion: The overall utilization of the urban health extension program was low compared to the national recommendation. Occupation, knowledge of participants towards UHEP, accessibility of health extension services, and participants' perception about the competency of HEWs were factors associated with utilization of UHEP. Therefore, awareness creation, in-service training, improving the accessibility of services and frequency of contact with mothers at the household level will increase the services utilization.

Keywords: urban health extension program, health service utilization, Gondar, Ethiopia

\section{Introduction}

The health extension program (HEP) is a new community-based healthcare delivery approach which is intended to improve the health of the community in Ethiopia, focusing on promotive, preventive, and few selected curative health services. ${ }^{1,2}$ There are four main themes in the program: disease prevention and control, family health, environmental hygiene, and health education and communication. ${ }^{3,4}$

The urban health service extension program in Ethiopia was initiated in 2009 by employing female health extension professionals. ${ }^{1}$ The approach is based on the 
assumption that access and quality of primary healthcare (PHC) in urban communities through the transfer of knowledge and skills to households. ${ }^{5,6}$ The main objectives of HEP are to improve equity and access to essential health interventions. Initiating community-based health insurance is supposed to be one of the priority strategies to address both equity and access related gaps by mobilizing, encouraging community participation, increasing health awareness, and skills within the community, improving utilization of PHC services, and promoting healthy lifestyles. ${ }^{7,8}$

Even though there is an encouraging trend of achievements, Ethiopia still has several poor vital health outcome indicators relative to other low-income countries. These poor outcomes are mainly due to low utilization of the HEP, which are attributed to the prevalence of preventable infectious and non-infectious diseases, complaints, nutritional deficiencies, and poor access to health services. ${ }^{3,4,6}$ The Ethiopian Demographic and Health Survey (EDHS) 2016 report showed that $88 \%$ of urban residents use untreated water and more than half (54\%) of family planning users were not informed about the potential sideeffects of the contraceptive method they used. ${ }^{9}$ Even though there is no UHEP utilization findings based cumulative value of packages in the northern part of Ethiopia, some indicators of the program at regional level in Tigray region showed that at least one antenatal care visit and skilled birth attendance were $65 \%$ and $11.6 \%$, respectively. ${ }^{10}$ A study finding at Mekelle, Tigray regional state, northern Ethiopia, showed that postnatal care utilization was found to be $32.2 \% .{ }^{11}$ Whereas, in the South nations, nationalities and peoples region (SNNPR), Ethiopia, the regional level antenatal care visit and skilled birth attendance achievements were 41 and $6.2 \%$, respectively. ${ }^{10}$ According to the study finding in Dale district, southern Ethiopia, $89.9 \%$ of mothers were not visited by the health extension workers (HEWs) for more than 6 months and more than threequarters gave birth at home. ${ }^{12}$

A study finding in Kefa zone, south Ethiopia, showed that the utilization of clean and safe delivery service was 19\%. ${ }^{13}$ A study done in Abuna Gindeberet District, Oromia Regional State, Ethiopia, showed that the utilization of health extension service was $39 \%{ }^{4}$

Different factors like socio-demographic characteristics, cultural beliefs and perception, traditional malpractices, the need for care, poor service accessibility, lack of in-service training, poor interpersonal relationships, knowledge, and attitude were variables that affect the utilization of HEP. ${ }^{6-8,14-18}$ However, the utilization of the UHEP and its associated factors remain unstudied in northwest Ethiopia. Hence, looking for utilization of the urban health extension program and its associated factors are the critical component of service provision and healthcare quality improvement in the study area, and the finding may give valuable information for policymakers, program coordinators, and researchers.

\section{Patients and Methods Study Design and Setting}

A community-based cross-sectional study design was employed from March 15 to May 30, 2019, in Gondar administrative city, which is one of the three metropolitan cities in Amhara national regional state. The city is located 176 and 755 kilometers from Bahir-Dar, the capital city of the region, and Addis Ababa, the capital city of Ethiopia, respectively. According to the city administration report, Gondar administrative city has 390,644 residents, of which 194,541 are females. According to the Gondar Administrative city health office report, 90,847 households are residing in the city. The city is divided into 12 subcities and 22 kebeles (the lowest administrative unit), and two urban health extension professionals are employed for each kebele.

\section{Population and Sampling Procedures}

All mothers in Gondar city administration were the source population, whereas mothers in randomly selected subcities were the study population. Mothers who were greater than or equal to 18 years old and living in the selected households for more than 6 months were included in the study.

The sample size was determined by using the single population proportion formula $\left(n=\frac{P(1-P)\left(Z_{\alpha / 2}\right)^{2}}{d^{2}}\right)$ by using a $52.7 \%$ proportion $(\mathrm{P})$ of urban health services extension program utilization taken from a study conducted in south Ethiopia, ${ }^{15}$ 95\% confidence limit (CI), 5\% marginal error (d), 1.5 design effect, and 10\% non-response rate. Then the final sample size was found to be 632 .

A multi-stage sampling technique was used. First, four sub-cities (30\% of the total sub-cities) were selected randomly by using lottery method. Then, the sample was allocated proportionally to each selected sub-city based on the estimated households. Eventually, study participants were selected using systematic sampling technique. 


\section{Variables and Measurements}

The dependent variable of the study was the utilization of urban health service extension program. The independent variables were socio-demographic characteristics (age, marital status, educational status, monthly income, religion, and occupation), knowledge and attitude of respondents about HEP, and perception of participants about HEWs (competency, interpersonal relationship, and ways of communication, time spent, and access to health extension workers).

Utilization of UHEP was measured by women's service-related contact with urban health extension professionals for the 15 health extension packages at health facilitates or home at least once in the previous 6 months prior to the study period. ${ }^{1}$ Accordingly, women who have gotten services more than or equal to $75 \%$ of the packages were considered as "utilized"; otherwise as "not utilized".

Knowledge was measured using seven items of the urban health extension program-related questions. Participants who scored greater than or equal to $75 \%$ of the given questions were considered as having satisfactory knowledge and otherwise having unsatisfactory knowledge. $^{5}$ The Cronbach alpha value for the seven items of the questions was 0.942 .

Attitude was measured using six items of questions with a 5-point Likert scale (1=strongly disagree, $2=$ disagree, $3=$ neutral, $4=$ agree, and $5=$ strongly agree). Participants who scored greater than or equal to the mean score (22.2) were considered as having a favorable attitude and below the mean score were considered as having an unfavorable attitude. The Cronbach alpha value for the six items of questions was $0.673 .{ }^{19}$

\section{Data Collection Tools and Procedures}

After reviewing relevant studies, an intervieweradministered structured questionnaire was developed. ${ }^{20}$ The questionnaire was prepared in English first and translated to the local language (Amharic) and then back to English to check its consistency. Five aspects of perception questions were used to measure the perception of respondents on UHEP. Four diploma nurses and two bachelor degree holder nurses were employed for data collection and supervision, respectively. One day training was given on the basic techniques of data collection and a pre-test was conducted on 32 women ( $5 \%$ of the sample size) in Bahir Dar administrative city (one of the neighboring city administrations with similar characteristics).

\section{Data Processing and Analysis}

The collected data were entered and cleaned using Epi info version 7 and analyzed using SPSS version 20. Descriptive statistics and binary logistic regression analyses were computed. Variables with a $P$-value of less than 0.2 during the bi-variable logistic regression analysis were taken for multi-variable logistic regression analysis. In the final multi-variable logistic regression analysis, AOR with 95\% CI and a $P$-value of less than 0.05 were used to declare statistically significance independent variables within the urban health service extension program utilization.

\section{Ethical Considerations}

Ethical clearance was obtained from the Ethical Review Board of the Institute of Public Health, University of Gondar (Ref. No. IPH/180/06/210). A supporting letter was obtained from Gondar administrative city health office (Ref. No. GCA/04). Participants of the study were informed about their right to withdraw from the study at any time. Finally, informed written consent was obtained before data collection. Confidentiality and anonymity of study participants were safeguarded throughout the entire study by using a non-personal identifier and the study was conducted in accordance with the Declaration of Helsinki.

\section{Results \\ Socio-Demographic Characteristics of Participants}

A total of 626 participants participated in the study. The majorities $(41.9 \%)$ of the study participants were between 27 and 35 years old and nearly three-fifths $(59.7 \%)$ of them were married. Regarding educational status, more than half (55.4\%) of the respondents had a certificate and above and religiously two-thirds $(66.6 \%)$ of the participants were Orthodox Christian followers. As to their occupational status, two-fifths (40.4\%) of the study participants were government employees (Table 1).

\section{Participants Knowledge and Attitude Towards the UHEP}

Participants' knowledge of UHEP was measured on health service extension program packages. Accordingly, about $65.3 \%$ of the participants scored more than or equal to $75 \%$ for the knowledge related questions. Thus, almost two-thirds $(65.3 \%)$ of the participants had satisfactory knowledge about the UHEP. Similarly, the mean score of 
Table I Sociodemographic Characteristics, Participants' Perception, and Urban Health Extension Program Utilization of the Participants in Gondar Administrative City, Northwest Ethiopia, $2019(\mathrm{~N}=626)$

\begin{tabular}{|c|c|}
\hline Variables & $\begin{array}{l}\text { Percentage } \\
\text { (\%) }\end{array}$ \\
\hline \multicolumn{2}{|l|}{ Age in years } \\
\hline $18-26$ & 8.1 \\
\hline $27-35$ & 41.9 \\
\hline $36-44$ & 34.0 \\
\hline $45-53$ & 10.7 \\
\hline+53 & 5.3 \\
\hline \multicolumn{2}{|l|}{ Marital status } \\
\hline Married & 59.7 \\
\hline Single & 19.2 \\
\hline Divorced & 13.7 \\
\hline Widowed & 7.4 \\
\hline \multicolumn{2}{|l|}{ Religion } \\
\hline Orthodox & 66.6 \\
\hline Muslim & 30.0 \\
\hline Protestant & 3.4 \\
\hline \multicolumn{2}{|l|}{ Educational status } \\
\hline Unable to read and write & 16.8 \\
\hline Able to read and write & 6.5 \\
\hline Primary school (grade I-8) & 6.1 \\
\hline Secondary school (grade 9-12) & 15.2 \\
\hline Certificate and above & 55.4 \\
\hline \multicolumn{2}{|l|}{ Occupation } \\
\hline Government employee & 40.4 \\
\hline Private employee & 22.0 \\
\hline House wife & 27.2 \\
\hline Merchants & 10.4 \\
\hline \multicolumn{2}{|l|}{$\begin{array}{l}\text { Perception of mothers on interaction with } \\
\text { UHEPs }\end{array}$} \\
\hline Perceived good technical competency & 55.3 \\
\hline Perceived good interpersonal relationship & 53.5 \\
\hline Perceived good time spent & 58.3 \\
\hline Perceived good ways of communication & 45.8 \\
\hline $\begin{array}{l}\text { Perceived good accessibility of health extension } \\
\text { workers }\end{array}$ & 48.4 \\
\hline \multicolumn{2}{|l|}{ Health service utilization } \\
\hline \multicolumn{2}{|l|}{ Family health } \\
\hline Immunization advice & 72.4 \\
\hline Maternal and child nutritional advice & 21.1 \\
\hline Family planning advice & 38.5 \\
\hline Pregnancy and delivery care & 32.6 \\
\hline Adolescent reproductive health advice & 28.6 \\
\hline $\begin{array}{l}\text { Personal hygiene and environmental sanitation } \\
\text { Housing and environmental sanitation }\end{array}$ & 43.8 \\
\hline
\end{tabular}

(Continued)
Table I (Continued).

\begin{tabular}{|l|l|}
\hline Variables & $\begin{array}{l}\text { Percentage } \\
\text { (\%) }\end{array}$ \\
\hline Solid and liquid west disposal & 56.2 \\
Latrine construction and usage & 58.0 \\
Water and food safety & 25.1 \\
\hline Disease prevention and control & \\
Prevention of malaria & 30.7 \\
Prevention of diarrheal diseases & 82.4 \\
Prevention of HIV/AIDS/TB & 73.8 \\
Prevention of non-communicable diseases & 16.0 \\
Mental health education & 6.7 \\
First aid services & 5.6 \\
\hline
\end{tabular}

study participants' attitudes towards UHEP was 22.2, and the vast majority $(88.2 \%)$ of participants scored above or equal to the mean value. Thus, a large fraction (88.2\%) of participants had a favorable attitude towards the urban health service extension program.

\section{Perceived Interpersonal Relationship, Time Spent, Competence, and Accessibility}

Nearly $54 \%$ of the respondents perceived that health extension professionals had a good interpersonal relationship with women. About $55.3 \%$ of the study participants perceived and reported that HEPs were competent and the majority $(58.3 \%)$ of them spent sufficient time with mothers. However, more than half $(51.6 \%)$ of the participants perceived there was poor accessibility of services (Table 1).

\section{Utilization of the Urban Health Extension Program}

In this study, utilization of UHEP was assessed based on the major program thematic areas and its respective individual packages. Thus, the overall utilization of the urban health service extension program in Gondar administrative city was found to be $59.5 \%(95 \% \mathrm{Cl}=55.8-63.6)$.

Regarding each thematic area, immunization advice $(72.4 \%)$ and maternal and child nutritional advice (21.1\%) were the highest and lowest performed in the family health packages, respectively. In the area of personal hygiene and environmental sanitation, latrine construction and use were the most highly utilized package (58\%) whereas water and food safety were the least implemented 
(25.1\%) health service extension program package. Prevention of diarrheal disease was the most highly utilized $(82.4 \%)$ part of disease prevention and the control group of UHEP. However, mental health education (6.7\%) and providing first aid services (5.6\%) were the least implemented parts of the program in general (Table 1).

\section{Factors Associated with UHEP Utilization}

In the multivariable logistic regression analysis: occupation, mothers' knowledge about UHEP, mothers' perception about the accessibility of health extension workers, and mothers' perception about UHEWs competency were variables significantly associated with the utilization of UHEP urban health service extension program.

Accordingly, mothers employed in the private sector, housewives, and merchants were $63 \%(\mathrm{AOR}=0.37,95 \%$ $\mathrm{Cl}=0.21-0.63), 64 \%(\mathrm{AOR}=0.36,95 \% \mathrm{Cl}=0.20-0.64)$, and $92 \%(\mathrm{AOR}=0.08,95 \% \mathrm{Cl}=0.03-0.17)$ less likely to utilize urban health service extension program as compared to governmental employees, respectively. Participants who had satisfactory knowledge towards the urban health service extension program were 4.37-times more likely to utilize the program as compared to those who had unsatisfactory knowledge ( $\mathrm{AOR}=4.37,95 \% \mathrm{Cl}=2.73-6.96)$. Participants who perceived health extension workers as competent were 1.97-times more likely to utilize the program as compared to their counterparts $(\mathrm{AOR}=1.97$, $95 \% \mathrm{Cl}=1.22-3.18$ ). Moreover, those who perceived that access to health extension workers was good were 1.68times more likely to utilize urban health service extension programs than those who perceived it as poor $(\mathrm{AOR}=1.68$, 95\% CI=1.02-2.74) (Table 2).

\section{Discussion}

The amount of women who utilized the urban health service extension program accounts was 59.5\%. This finding was higher than studies conducted at Abuna Gindeberet and Dera districts, Oromia regional state, Ethiopia (39\% and 41.8\%), respectively. ${ }^{4,21}$ The possible reason might be the study site difference, the study conducted in Gindeberet district was from both rural and urban areas, whereas the study in Dera district was conducted on rural areas that may reduce the service utilization. The finding of this study was in line with another study conducted in the urban community in Ethiopia $(57.1 \%){ }^{22}$ But this finding is much lower than those of studies in Gullele sub-city administration, Addis Ababa, Ethiopia (86\%), and Bishoftu town, Oromia regional state, central Ethiopia (72.8\%). ${ }^{1,5}$ The possible justification might be due to the difference in uptake of the urban health service extension program which implies that the community still focus on curative healthcare services in the study area. The other possible reason could be the difference in the extent of supportive supervision and on-job training which was supported by systematic review in Ethiopia, where limited supportive supervision was one of the challenges to implement the health service extension program. ${ }^{23}$

In this study, mothers employed in the private sector, housewives, and merchants were 63, 64, and 92\% less likely to utilize the program as compared to governmental employees, respectively. The finding is supported by that of a study finding in Abuna Gindeberet district, Oromia regional state, Ethiopia, and showed that Governmental employees were 3.79-times more likely to utilize the urban health service extension program as compared to farmers. ${ }^{4}$ The possible reason might be due to the result of inter-sectoral collaboration between the health sector and other governmental sectors that lead to high information access for governmental workers. In addition, some health extension packages like HIV/AIDS are considered as a cross-cutting issue in every governmental organization that could enhance the utilization of the program.

In this study, participants who had satisfactory knowledge were 4.37-times more likely to utilize the services as compared to participants who had unsatisfactory knowledge. The result is supported by a study conducted in Gullele subcity, administration, Addis Ababa, Ethiopia and showed that participants who had satisfactory knowledge were 1.5 times more likely to utilize the services as compared to participants who had unsatisfactory knowledge. ${ }^{5}$ On the other hand, it is comparable with the finding in Hadiya zone, south Ethiopia, participants who had adequate knowledge were 2.3-times more satisfied on services than their counterpart, ${ }^{19}$ the study was conducted in an urban community of Ethiopia participants who had the information about health service extension program were 2.13-times more likely to visit health centers than those who had no information. ${ }^{15}$ It was also supported by a study conducted among model households in Ethiopia which showed participants who had a good understanding about the program were 1.16-times more likely to utilize the services as compared to those who had poor understanding. ${ }^{22}$ The possible justification might be the result of frequent home visits and strong attention of the government towards the program.

In this study, participants who had good accesses to UHEP and who perceived HEWs were competent were 1.68-times and 1.97-times more likely to utilize the 
Table 2 Multivariable Logistic Regression Analysis of Factors for Utilization of Urban Health Extension Program in Gondar Administrative City, Northwest Ethiopia, 2019 ( $n=626)$

\begin{tabular}{|c|c|c|c|c|}
\hline \multirow[t]{2}{*}{ Variables } & \multicolumn{2}{|c|}{ Utilization Status } & \multirow[t]{2}{*}{ COR (95\%) } & \multirow[t]{2}{*}{ AOR (95\%Cl) } \\
\hline & Utilized (\%) & Not Utilized (\%) & & \\
\hline \multicolumn{5}{|l|}{ Marital status } \\
\hline Married & 38.5 & 61.5 & I & I \\
\hline Single & 35.8 & 64.2 & $1.12(0.73-1.72)$ & $1.28(0.74-2.21)$ \\
\hline Divorced & 52.3 & 47.7 & $0.57(0.36-0.92)$ & $0.55(2.93-1.01)$ \\
\hline Widowed & 43.5 & 56.5 & $0.8 I(0.44-I .5 I)$ & $0.65(0.30-1.42)$ \\
\hline \multicolumn{5}{|l|}{ Educational status } \\
\hline Unable to read and write & 59.0 & 41.0 & 1 & I \\
\hline Able to read and write & 46.3 & 53.7 & $\mathrm{I} .67(0.8 \mathrm{I}-3.45)$ & $1.32(0.53-3.26)$ \\
\hline Primary school (Grade I-8) & 36.8 & 63.2 & $2.47(|| 5-5.31)$. & $1.28(0.49-3.35)$ \\
\hline Secondary school (Grade 9-12) & 48.4 & 51.6 & $1.54(0.88-2.69)$ & $0.80(0.39-1.65)$ \\
\hline Certificate and above & 32.0 & 68.0 & $3.07(I .96-4.8 I)$ & $0.92(0.49-1.73)$ \\
\hline \multicolumn{5}{|l|}{ Occupation } \\
\hline Government employee & 18.2 & 81.2 & 1 & 1 \\
\hline Private employee & 39.8 & 60.2 & $0.34(0.21-0.54)$ & $0.37(0.2 \mathrm{I}-0.63)^{* *}$ \\
\hline Housewife & 57.6 & 42.4 & $0.16(0.11-0.25)$ & $0.36(0.20-0.64)^{* *}$ \\
\hline Merchants & 81.5 & 18.5 & $0.05(0.03-0.10)$ & $0.08(0.03-0.17)^{* * *}$ \\
\hline \multicolumn{5}{|l|}{ Attitude } \\
\hline Unfavorable & 58.1 & 41.9 & 1 & 1 \\
\hline Favorable & 37.9 & 62.1 & $2.78(1.39-3.73)$ & $0.87(0.47-1.59)$ \\
\hline \multicolumn{5}{|l|}{ Knowledge } \\
\hline Not satisfactory & 90.4 & 9.6 & 1 & 1 \\
\hline Satisfactory & 25.0 & 75.0 & $2.28(1.39-3.73)$ & $4.37(2.73-6.96)^{* *}$ \\
\hline \multicolumn{5}{|l|}{ Interpersonal relationship } \\
\hline Poor & 43.3 & 56.7 & 1 & 1 \\
\hline Good & 37.6 & 62.4 & $1.27(0.92-1.75)$ & $0.65(0.42-1.01)$ \\
\hline \multicolumn{5}{|l|}{ Ways of communication } \\
\hline Poor & 45.7 & 54.3 & I & I \\
\hline Good & 33.8 & 66.3 & $1.65(1.19-2.28)$ & $0.75(0.47-1.18)$ \\
\hline \multicolumn{5}{|l|}{ Levels of time spent } \\
\hline Less time & 56.7 & 43.3 & 1 & 1 \\
\hline Good time & 28.5 & 71.5 & $3.29(2.35-4.59)$ & $1.46(0.92-2.31)$ \\
\hline \multicolumn{5}{|l|}{ Competency } \\
\hline Not competent & 58.6 & $4 I .4$ & 1 & I \\
\hline Competent & 25.4 & 74.6 & $4.15(2.95-5.82)$ & $1.97(1.22-3.18)^{*}$ \\
\hline \multicolumn{5}{|l|}{ Accessibility } \\
\hline Not accessible & 57.6 & 42.4 & 1 & I \\
\hline Accessible & 21.8 & 78.2 & $4.88(3.43-6.92)$ & $1.68(1.02-2.74)^{*}$ \\
\hline
\end{tabular}

Notes: *Statically significant at a $P$-value $<0.05 ; * *$ Statically significant at a $P$-value $<0.001$.

Abbreviations: AOR, adjusted odds ratio; COR, crude odds ratio.

services than their counterpart, respectively. This result implies that there was a strong commitment among healthcare workers, good availability of drugs, equipment, and other supplies, strong supportive supervision, good interpersonal communication and in-service training that build trust and enhance utilization in the study area. 


\section{Strengths and Limitations of the Study}

Our study used enough sample size to generalize the findings. Even though we interviewed the women separately using a structured interviewer-administered questionnaire, still, there might be uncontrolled socially desirable biases and the women were interviewed in a relaxed way by giving more time and freedom about the last 6 months contact, however still there might also be recall bias.

\section{Conclusions}

Our study clearly showed that three-fifths of the respondents did not utilize the urban health extension program services provided by urban health extension professionals. Private sector employment, housewives, and merchants occupation affected the utilization negatively, whereas satisfactory knowledge about urban health service extension programs, good perception about the accessibility of health extension services, as well as the competency of health extension workers affected the utilization positively. Therefore, awareness creation about the urban health extension program, providing in service training, improving inter-personal relationships, improving the accessibility of services, promotion of services, and improving the frequency of contact with mothers at household level will increase the utilization of the urban health extension program.

\section{Data Sharing Statements}

All the data supporting the findings are within the manuscript. Additional detailed information and raw data are available from the corresponding author on reasonable request.

\section{Acknowledgment}

The authors would like to thank all the respondents for their willingness to participate in the study and giving valuable information. We are also grateful to Gondar city administrative health office for giving us a supportive letter and the University of Gondar, Institute of Public Health staff for their technical support. Finally, our appreciation goes to data collectors and supervisors for their unreserved contribution in the data collection process.

\section{Author Contributions}

All authors substantially contributed to the design, acquisition, analysis, and interpretation of data, drafting, revising, and final approval. Besides, all authors agreed to be accountable for all aspects of the work.

\section{Disclosure}

The authors confirmed that they had no conflicts of interest for this work and that no funding for this research was secured.

\section{References}

1. Gebreegziabher EA, Astawesegn FH, Anjulo AA, Kerie MW. Urban health extension services utilization in Bishoftu Town, Oromia Regional State, Central Ethiopia. BMC Health Serv Res. 2017;17 (1):195. doi:10.1186/s12913-017-2129-z

2. Kok MC, Broerse JEW, Theobald S, Ormel H, Dieleman M, Taegtmeyer M. Performance of community health workers: situating their intermediary position within complex adaptive health systems. Hum Resour Health. 2017;15(1):59. doi:10.1186/s12960-017-0234-z

3. Birhanu Z, Godesso A, Kebede Y, Gerbaba M. Mothers' experiences and satisfactions with health extension program in Jimma zone, Ethiopia: a cross sectional study. BMC Health Serv Res. 2013;13 (1):74. doi:10.1186/1472-6963-13-74

4. Kelbessa Z, Baraki N, Egata G. Level of health extension service utilization and associated factors among community in Abuna Gindeberet District, West Shoa Zone, Oromia Regional State, Ethiopia. BMC Health Serv Res. 2014;14:324. doi:10.1186/14726963-14-324

5. Mekonnen Girmay A, Evans M, Gari S, Gebremariam A, Reta M. Urban health extension service utilization and associated factors in the community of Gullele sub-city administration, Addis Ababa, Ethiopia. Int $J$ Commun Med Public Health. 2019;6:976. doi:10.18203/2394-6040.ijcmph20190580

6. Xu X, Huang X, Zhang X, Chen L. Family economic burden of elderly chronic diseases: evidence from China. Healthcare (Basel, Switzerland). 2019;7(3).

7. Witter S, Anderson I, Annear P, et al. What, why and how do health systems learn from one another? Insights from eight low- and middle-income country case studies. Health Res Policy Syst. 2019;17(1):9. doi:10.1186/s12961-018-0410-1

8. Chen L, Zhang $\mathrm{X}, \mathrm{Xu} \mathrm{X}$. Health insurance and long-term care services for the disabled elderly in China: based on CHARLS data. Risk Manag Healthc Policy. 2020;13:155-162. doi:10.2147/RMHP. S233949

9. Federal democratic republic of Ethiopia. Demographic and Health Survey. Centeral Statistics Agency; 2016.

10. Afework MF, Admassu K, Mekonnen A, Hagos S, Asegid M, Ahmed S. Effect of an innovative community based health program on maternal health service utilization in north and south central Ethiopia: a community based cross sectional study. Reprod Health. 2014;11(1):28. doi:10.1186/1742-4755-11-28

11. Gebrehiwot G, Medhanyie AA, Gidey G, Abrha K. Postnatal care utilization among urban women in northern Ethiopia: cross-sectional survey. BMC Women's Health. 2018;18(1):78. doi:10.1186/s12905018-0557-5

12. Negussie A, Girma G. Is the role of Health Extension Workers in the delivery of maternal and child health care services a significant attribute? The case of Dale district, southern Ethiopia. BMC Health Serv Res. 2017;17(1):641. doi:10.1186/s12913-017-2590-8

13. Bayou NB, Gacho YH. Utilization of clean and safe delivery service package of health services extension program and associated factors in rural kebeles of Kafa Zone, Southwest Ethiopia. Ethiop J Health Sci. 2013;23(2):79-89.

14. Shaikh BT, Hatcher J. Health seeking behaviour and health service utilization in Pakistan: challenging the policy makers. $J$ Public Health (Oxford, England). 2005;27(1):49-54. doi:10.1093/pubmed/fdh207

15. Yitayal M, Berhane Y, Worku A, Kebede Y. Health extension program factors, frequency of household visits and being model households, improved utilization of basic health services in Ethiopia. BMC Health Serv Res. 2014;14(1):156. doi:10.1186/1472-6963-14-156 
16. Carrasquillo O. Health Care Utilization. In: Gellman MD, Turner JR, editors. Encyclopedia of Behavioral Medicine. New York: Springer New York; 2013:909-910.

17. Cifaldi M. Factors affecting health services utilization in the medicare population: would providing prescription drug coverage to medicare recipients affect their use of health care resources? In: Irina F, Kent S, Alan S, editors. Investing in Health: The Social and Economic Benefits of Health Care Innovation. Vol. 14. Emerald Group Publishing Limited; 2001:119-141.

18. Li Y-N, Nong D-X, Wei B, Feng Q-M, Luo H-Y. The impact of predisposing, enabling, and need factors in utilization of health services among rural residents in Guangxi, China. BMC Health Serv Res. 2016;16(1):592. doi:10.1186/s12913-016-1825-4

19. Sibamo EL, Berheto TM. Community satisfaction with the urban health extension service in South Ethiopia and associated factors. BMC Health Serv Res. 2015;15(1):160. doi:10.1186/s12913-0150821-4
20. Ouedraogo MO. Maternal and Child Health in Jimma Zone, Ethiopia: Predictors, Barriers and Strategies for Improvement. Université d'Ottawa/University of Ottawa; 2018.

21. Tadesse Zeleke A. Factors associated with Health Extension Service utilization in Dera District, Oromia, Ethiopia: a multi level analysis. Am J Theor Appl Stat. 2019;8(3):85-93. doi:10.11648/j.ajtas. 20190803.11

22. Tafesse N, Gesessew A, Kidane E. Urban health extension program model housing and household visits improved the utilization of health Services in Urban Ethiopia: a community-based cross-sectional study. BMC Health Serv Res. 2019;19(1):31. doi:10.1186/s12913-019-3868-9

23. Assefa Y, Gelaw YA, Hill PS, Taye BW, Van Damme W. Community health extension program of Ethiopia, 2003-2018: successes and challenges toward universal coverage for primary healthcare services. Global Health. 2019;15(1):24. doi:10.1186/s12992-019-0470-1
Risk Management and Healthcare Policy

\section{Publish your work in this journal}

Risk Management and Healthcare Policy is an international, peerreviewed, open access journal focusing on all aspects of public health, policy, and preventative measures to promote good health and improve morbidity and mortality in the population. The journal welcomes submitted papers covering original research, basic science, clinical \& epidemiological studies, reviews and evaluations,
Dovepress

guidelines, expert opinion and commentary, case reports and extended reports. The manuscript management system is completely online and includes a very quick and fair peer-review system, which is all easy to use. Visit http://www.dovepress.com/testimonials.php to read real quotes from published authors. 